\title{
Blood pressure measurement at screening and in general practice
}

\author{
D. H. BARLOW, D. G. BEEVERS, V. M. HAWTHORNE, HELEN D. WATT, \\ AND G. A. R. YOUNG \\ From the M.R.C. Blood Pressure Unit, Western Infirmary, Glasgow, and the \\ Department of Community Medicine, University of Glasgow
}

As part of an epidemiological study of hypertension, an analysis was made of the general practitioner records of all attenders at a screening survey. A blood pressure recording, made before screening, was found in 37.9 per cent of cases. The pressures obtained correlated well with those obtained by the screening unit, though the practitioners' readings tended to be lower. Further cases of hypertension were found, not diagnosed by the screening unit; the estimate made of the prevalence of hypertension at the survey could be corrected by inclusion of these cases.

Chest pain, headaches, lightheadedness, and dizziness were common reasons for blood pressure measurement in general practice, but these symptoms were not associated with a rise in the blood pressure; symptoms were not helpful in the diagnosis of hypertension.

Some form of screening programme is necessary to detect cases of hypertension. This could be carried out by general practitioners.

The place of screening surveys in the detection of cases of hypertension is controversial (Sackett, 1974; Hawthorne, 1975; Turner and Ball, 1975; Sackett and Holland, 1975), and the point may not be resolved until current clinical trials show whether the large number of cases with mild hypertension will benefit from treatment (Peart, 1973; Abernethy, 1974; Miall and Brennan, 1975; Wilhelmsen, 1975). If treatment is shown to be worth while, then screening programmes may be necessary as most cases are symptomless. It is not known, however, what proportion of the population has already had blood pressures measured in the course of routine clinical practice, or what proportion of hypertensives are already diagnosed. We report the results of an examination of general practitioner records of 3001 subjects all of whom subsequently attended an epidemiological screening survey. A study was made of the frequency of and reasons for blood pressure recording in general practice, together with a comparison of blood pressures measured in the two ways. Furthermore, the figures for the prevalence of hypertension could then be adjusted to include the general practitioner data.

Received for publication 24 May 1976

\section{Methods}

An epidemiological screening survey was carried out by the Glasgow M.M.R. cardiorespiratory screening unit (Hawthorne et al., 1972) in the Burgh of Renfrew during March and April 1972. 3810 residents aged 45 to 64 were eligible and $3001(78.8 \%)$ attended. Blood pressure was measured using the London School of Hygiene sphygmomanometer (Rose et al., 1964) and data on the prevalence of hypertension at screening are published elsewhere (Hawthorne et al., 1974). As part of the study, with the consent of the 9 general practitioners of the Burgh, none of whom had previously had a special interest in hypertension, an examination was made of the N.H.S. medical records of all subjects screened.

All blood pressure readings made before the screening survey were recorded, with the reasons for measurement, where these were apparent. Detailed information was also obtained of antihypertensive therapy up until the time of screening. Statistical analysis of the general practitioner and screening readings was carried out on an I.B.M. 360168 computer. 
Table 1 Frequency of prior blood pressure measurement in relation to age, sex, and height of the blood pressure at screening

\begin{tabular}{|c|c|c|c|c|c|c|c|}
\hline \multirow{3}{*}{$\begin{array}{l}\text { Diastolic blood } \\
\text { pressure at } \\
\text { screening ( } \mathrm{mmHg} \text { ) }\end{array}$} & \multicolumn{7}{|c|}{ Number (and \%) with previous blood pressure recording in general practitioners' notes } \\
\hline & \multicolumn{3}{|l|}{ Males } & \multicolumn{3}{|l|}{ Females } & \multirow{2}{*}{$\begin{array}{l}\text { Total } \\
(M+F)\end{array}$} \\
\hline & Age 45-54 & Age 55-64 & Total & Age 45-54 & Age 55-64 & Total & \\
\hline $\begin{array}{c}\leq 59 \\
60-69 \\
70-79 \\
80-89 \\
90-99 \\
100-109 \\
110-119 \\
120-129 \\
\geq 130\end{array}$ & $\begin{array}{r}1(33.3 \%) \\
13(52.0 \%) \\
37(23.1 \%) \\
70(28.0 \%) \\
47(27.3 \%) \\
27(36.5 \%) \\
7(41.2 \%) \\
3(50.0 \%) \\
1(20.0 \%)\end{array}$ & $\begin{array}{r}2(33.3 \%) \\
11(36.6 \%) \\
34(31.8 \%) \\
58(32.5 \%) \\
59(41.8 \%) \\
27(36.0 \%) \\
10(43.5 \%) \\
3(33.3 \%) \\
4(57.1 \%)\end{array}$ & $\begin{array}{r}3(33.3 \%) \\
24(42.9 \%) \\
71(26.6 \%) \\
128(30.3 \%) \\
106(33.9 \%) \\
54(36.2 \%) \\
17(42.5 \%) \\
6(40.0 \%) \\
5(41.7 \%)\end{array}$ & $\begin{array}{c}4(44.4 \%) \\
22(37.3 \%) \\
72(35 \cdot 1 \%) \\
98(36.8 \%) \\
78(42.9 \%) \\
20(38.5 \%) \\
19(76.0 \%) \\
2(50 \%) \\
0(-)\end{array}$ & $\begin{array}{c}0(-\overrightarrow{ }) \\
12(63 \cdot 2 \%) \\
47(40 \cdot 2 \%) \\
90(41 \cdot 9 \%) \\
86(50 \cdot 6 \%) \\
54(53.5 \%) \\
20(60.6 \%) \\
4(44 \cdot 4 \%) \\
3(60 \%)\end{array}$ & $\begin{array}{r}4(33 \cdot 3 \%) \\
34(43 \cdot 6 \%) \\
119(37 \cdot 0 \%) \\
188(39 \cdot 1 \%) \\
164(46 \cdot 6 \%) \\
74(48 \cdot 4 \%) \\
39(67 \cdot 2 \%) \\
6(46 \cdot 2 \%) \\
3(42.9 \%)\end{array}$ & $\begin{array}{r}7(33.3 \%) \\
58(43.3 \%) \\
190(32.3 \%) \\
316(35.0 \%) \\
270(40.6 \%) \\
128(42.4 \%) \\
56(57 \cdot 1 \%) \\
12(42.9 \%) \\
8(42.1 \%)\end{array}$ \\
\hline Total & $206(28 \cdot 8 \%)$ & $208(36 \cdot 4 \%)$ & $414(32 \cdot 2 \%)$ & $315(39 \cdot 2 \%)$ & $316(47 \cdot 0 \%)$ & $631(42 \cdot 8 \%)$ & $1045(37 \cdot 9 \%)$ \\
\hline
\end{tabular}

\section{Results}

General practitioners' records were traced in $2760(92 \%)$ of the 3001 subjects attending. Of the 241 cases whose records were not located, 141 attended practitioners outside Renfrew and 41 had died: in only 59 cases were the notes not accounted for.

\section{FREQUENCY OF BLOOD PRESSURE MEASUREMENT}

$1045(37.9 \%)$ of the 2760 records examined contained a blood pressure reading taken before the screening (Table 1). The frequency of recording among women (42.8\%) was higher than among men $(32 \cdot 2 \%)$, reflecting women's greater frequency of visiting their general practitioners (Beevers et al., 1975). Older subjects (aged 55 to 64) had had their blood pressure recorded more frequently than subjects aged 45 to 54 . No data were available on the length of time patients had been on individual general practitioner's lists.

The frequency of blood pressure recording was also slightly higher among subjects whose blood pressure was high at the screening survey (Table 1) though the proportion was usually below 50 per cent.

While this may be the result of a tendency for hypertensives to have their blood pressure measured more often than normotensives, it is also possible that practitioners had measured blood pressures more often but recorded them in the notes only when they were found to be raised.

Fig. 1 shows the year of the earliest blood pressure measurement in the notes. The older subjects appear to have their blood pressure reading earlier, but it is suspected that some of the earlier sheets in the NHS records folder may have been lost or discarded, thus accounting for the apparently
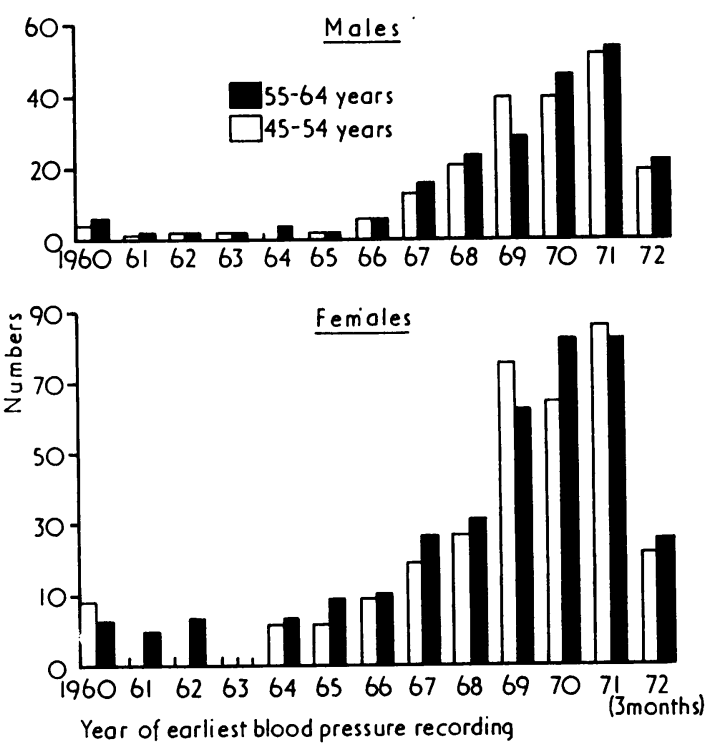

Fig. 1 The year of the earliest blood pressure reading found in patients' notes.

low frequency of blood pressure recording before 1967. In addition, the increasing rate during 1971 and 1972 may reflect an increased interest in blood pressure by the practitioners, especially at the time that the screening survey was being planned. Within the age range studied (45 to 64 years), routine obstetrical screening and the use of oral contraceptives was not a factor to explain the higher rates of blood pressure recording among women.

In 189 subjects a recording had been made after 1 January 1972, i.e. within two or three months of the screening in March and April. These readings correlated closely with the screening readings 


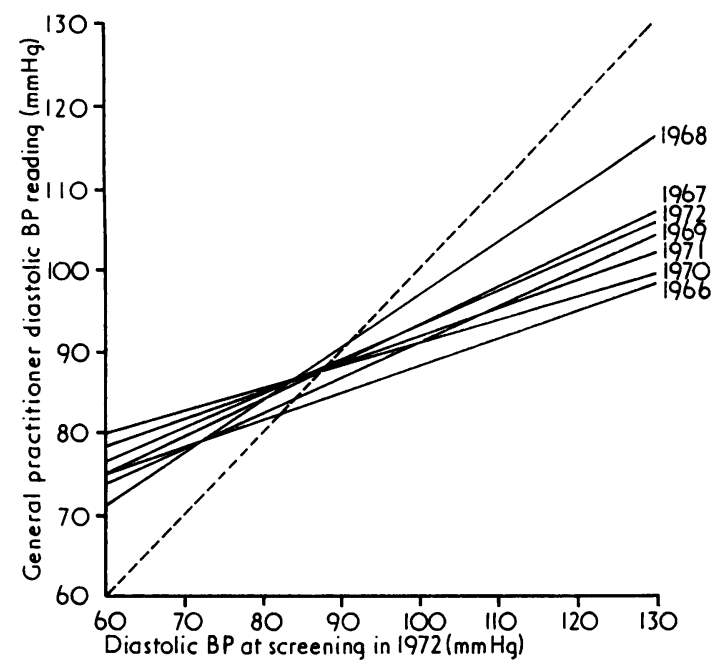

Fig. 2 Regression lines relating earliest diastolic blood pressure measurement in general practice to blood pressure at screening in 1972.

$(\mathrm{r}=+0.5411, \mathrm{P}<0.001)$ and similar correlations were obtained for earlier years though there was no tendency for the regression lines to move nearer to $45^{\circ}$ with the passage of time (Fig. 2). General practitioner readings taken within three months of screening in 1972 tended to be lower than the screening readings at higher levels of pressure while
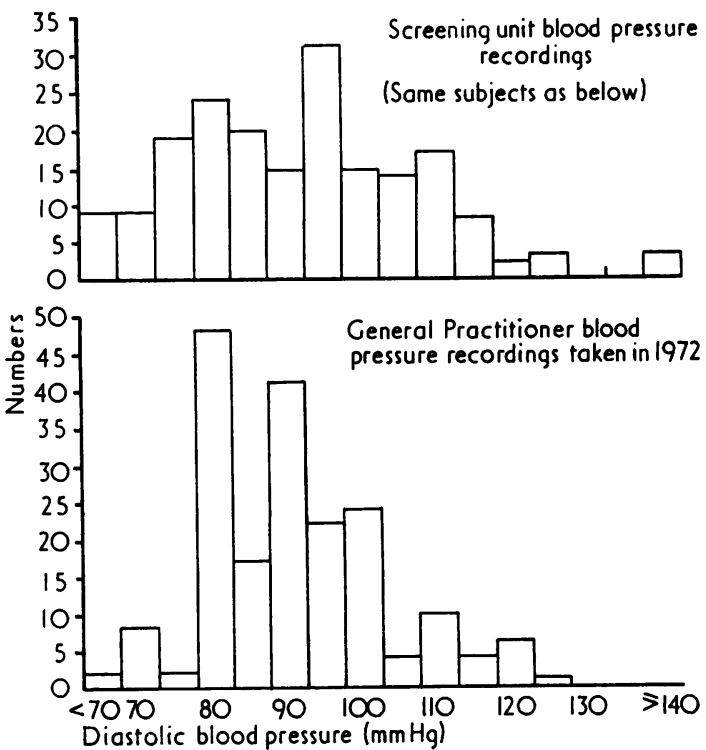

Fig. 3 Comparison of diastolic blood pressure recordings in 1972 in general practice and at screening (189 subjects).

the opposite was the case at lower pressures (Fig. 3). The former may reflect the quieter and more relaxed conditions under which general practitioners measure blood pressure in their clinics, and the

Table 2 Reasons for blood pressure measurement

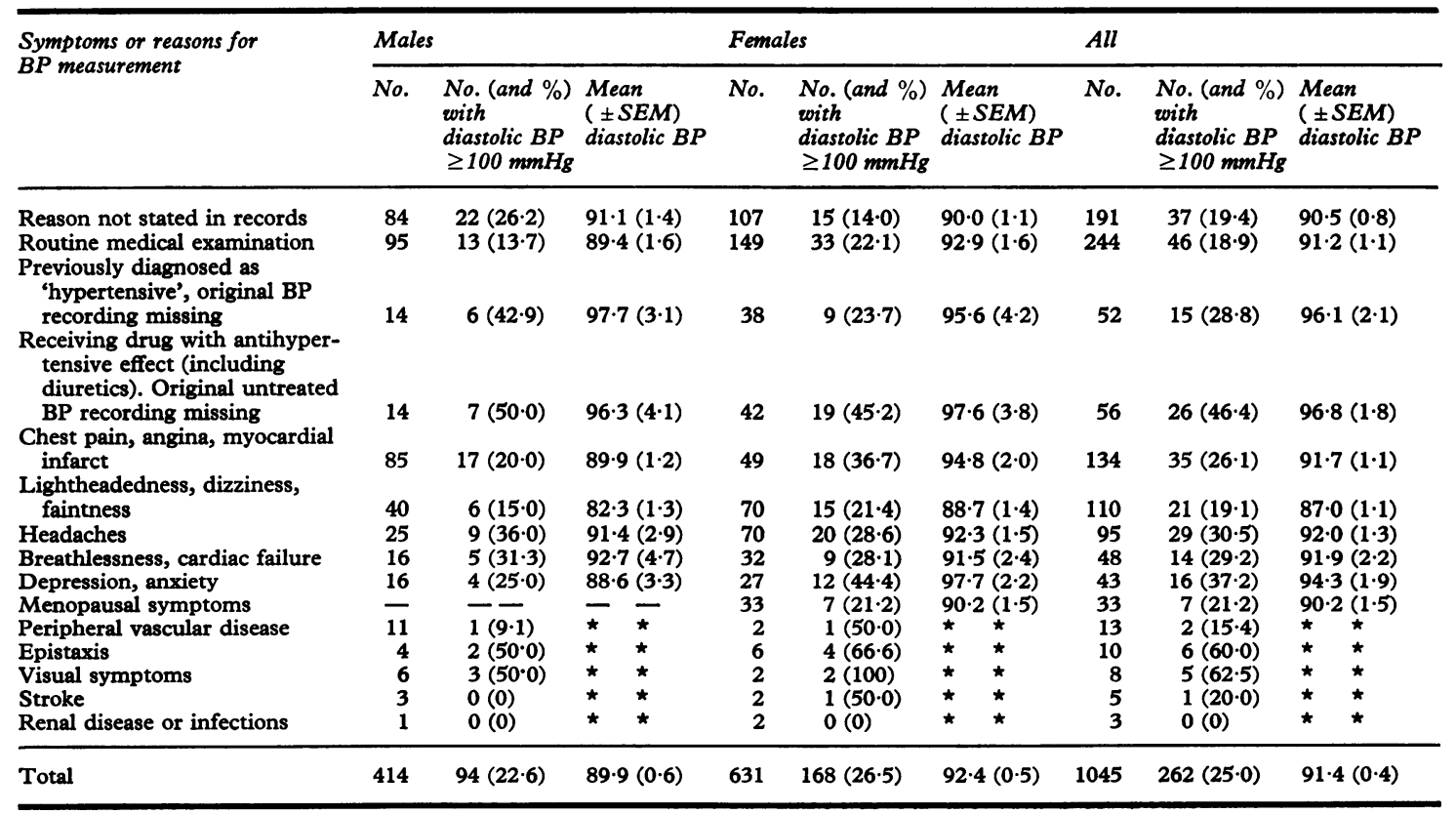

«Too few cases for means to be calculated. 
latter a tendency to measure the pressure less accurately using conventional sphygmomanometers when the diastolic blood pressure is found to be below $90 \mathrm{mmHg}$.

\section{SYMPTOMS AND BLOOD PRESSURE}

The reasons or symptoms leading to the earliest blood pressure recording are shown in Table 2. Often no reason was given; routine medical examination by practitioners or blood pressure measurement recorded in hospital letters were also a common explanation.

Chest pain, lightheadedness, dizziness, fainting, headache, breathlessness, and symptoms of anxiety, depression, or the menopause were common, while stroke, epistaxis, and renal symptoms were rare. There were no significant differences in the blood pressures recorded for each reason or symptom among men or women, though men complained more frequently of chest pain, and women with depression or anxiety tended to have slightly higher diastolic blood pressure.

\section{PREVALENCE OF HYPERTENSION}

At the screening survey, 468 subjects $(15.6 \%)$ had diastolic pressures of $100 \mathrm{mmHg}$ or more. In 448 of these the records were traced and $204(45.5 \%)$ had a previous blood pressure recording in their notes, though only $138(30.8 \%)$ had a previous recording of $100 \mathrm{mmHg}$ or more. A further 60 cases who were receiving antihypertensive therapy had diastolic pressures less than $100 \mathrm{mmHg}$ at screening, and it is reasonable to include these in calculations of the prevalence of hypertension. Of this total of 508 cases, $264(62.0 \%)$ had previous blood pressure readings in their notes, but in only $198(39.0 \%)$ was this $100 \mathrm{mmHg}$ or more; a total of $134(26.4 \%)$ were receiving antihypertensive therapy. However, examination of the records also revealed a further 132 cases whose diastolic pressure was less than $100 \mathrm{mmHg}$ at screening but who had previous readings above this level. None of these was receiving antihypertensive therapy. If these cases are added then the grand total is 640 hypertensives, past or present, which is equivalent to 23.2 per cent of the population studied. Of these, $396(61.9 \%)$ had previous blood pressure recordings in their notes, though in only 330 $(51 \cdot 6 \%)$ was this $100 \mathrm{mmHg}$ or more.

\section{THERAPY}

A total of 134 subjects were receiving antihypertensive therapy at the time of the screening. Fig. 4 shows the blood pressures of these patients, as judged by the screening readings and the most recent general practitioner reading.

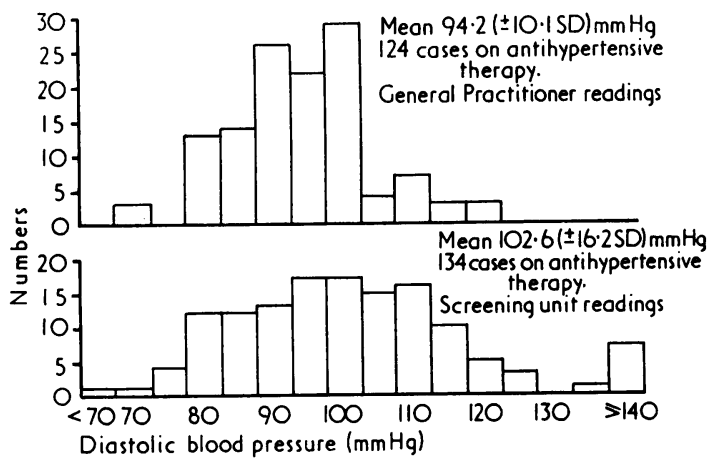

Fig. 4 General practitioner and screening diastolic blood pressure recordings in cases receiving antihypertensive therapy. Ten of the 134 cases who were on treatment at the time of screening had just started this and had no general practitioner blood pressure reading while on treatment.

The diastolic pressure was greater than $99 \mathrm{mmHg}$ in 56 per cent of subjects at screening, but in only 37 per cent when seen by the general practitioner. As before, this may reflect the more basal conditions under which the practitioners measure blood pressures, but observer bias may also be present. Antihypertensive drugs used included methyldopa alone in 36 per cent and a thiazide diuretic in 24.4 per cent. Beta-adrenergic receptor blocking drugs were used in only 1.5 per cent of cases, and it is of interest that 14.5 per cent of cases were receiving a rauwolfia derivative. These represent drugs chosen in 1972, before the recent increase in interest in the use of beta-adrenergic receptor blocking drugs in the treatment of hypertension.

\section{Discussion}

By relating the information from the general practitioner records search with the data from the screening examination, a more complete picture has been obtained of the prevalence of hypertension. This confirms that hypertension is very common in the West of Scotland (Hawthorne et al., 1969) and that a large number of cases are undiagnosed. Direct comparison with other studies is difficult, as in some of these the figures for prior diagnosis were based on patients' awareness of hypertension, rather than direct study of the clinicians' records (Wilber and Barrow, 1972; Schoenberger et al., 1972). It is possible that more patients may have had their blood pressures measured in the past, but, especially when the blood pressure recorded was not raised, it may not have been written down in the limited space available in the notes or, as stated earlier, the older 
notes may have been lost. There was, however, no evidence to support Sackett's (1974) contention that the majority of hypertensives detected at screening have already had a blood pressure check. This view, however, may be true of screening examinations among casual attenders rather than studies of defined populations (Wilber and Barrow, 1972; Schoenberger et al., 1972; Silverberg et al., 1974; Schnohr and Hansen, 1975).

The lack of association of hypertension with any particular symptom makes it unlikely that hypertensives present to their doctor with a diagnostically useful complaint. The relation between headache and hypertension is not a close one. Al Badran et al. (1970) found no relation except in severe cases and others (Waters, 1971; Weiss, 1972) have found no relation at all. More recently, Bulpitt et al. (1976) have suggested that headache, lightheadedness, and faintness are related to hypertension. However, Stewart (1953) has drawn attention to the importance of awareness of the diagnosis in relation to reported symptoms, and this may account for the differences found when comparing studies of hospital patients with studies of populations. However, headache is a common reason for blood pressure measurement in general practice (Hodes et al., 1975). Epistaxis is also commonly related to hypertension (Mitchell, 1959) though in this study it was an uncommon reason for blood pressure measurement.

It is also commonly held that anxiety and depression are related to hypertension. In this study the slightly higher blood pressures among female subjects presenting with these symptoms were not statistically significant. While some studies have suggested that hypertension may be related to stress (Robinson, 1962; Sainsbury, 1964) others have not confirmed this (Davies, 1970). Hypertensives certainly show features of anxiety on being told of their raised blood pressures (Stewart, 1953).

Antihypertensive therapy, where given, frequently failed to reduce diastolic blood pressure to below $100 \mathrm{mmHg}$. While any reduction is worth while (Hamilton et al., 1964; Veterans Administration Co-Operative Study Group, 1967, 1970), prognosis is likely to be better if the diastolic blood pressure is maintained below $100 \mathrm{mmHg}$ (Beevers et al., 1973; Taguchi and Freis, 1974).

We conclude that in routine general practice in Britain under the National Health Service less than half of the middle-aged population have their blood pressures measured and that only about 50 per cent of hypertensives are diagnosed. To detect the remainder, some form of screening programme is necessary, though this might be carried out by the practitioners themselves (Beevers, et al., 1975). Such surveys as have been conducted have, in general, proved successful (Sinclair, 1969; Hart, 1970).

We are grateful for the co-operation of the Provost and Town Council, and the family doctors of Renfrew, as well as many voluntary organisations. The work was supported by the Renfrewshire King Edward Memorial Trust, the Scottish Home and Health Department, and the Greater Glasgow Health Board.

\section{References}

Abernethy, J. D. (1974). The Australian national blood pressure study. Medical fournal of Australia, 1, 821.

Al Badran, R. H., Weir, R. J., and McGuiness, J. B. (1970). Hypertension and headache. Scottish Medical fournal, 15, 48.

Beevers, D. G., Fairman, M. J., Hamilton, M., and Harpur, J. E. (1973). The influence of antihypertensive treatment over the incidence of cerebral vascular disease. Postgraduate Medical fournal, 49, 905.

Beevers, D. G., Hawthorne, V. M., and Sinclair, R. G. (1975). In Pathophysiology and Management of Arterial Hypertension, p. 263. Ed. by G. Berglund, L. Hansson, and L. Werkö. A. B. Hässle, Mölndal, Sweden.

Bulpitt, C. J., Dollery, C. T., and Carne, S. (1976). Changes in symptoms of hypertensive patients after referral to hospital clinic. British Heart fournal, 38, 121.

Davies, M. (1970). Blood pressure and personality. Fournal of Psychosomatic Research, 14, 89.

Hart, J. T. (1970). Semicontinuous screening of a whole community for hypertension. Lancet, 2, 223.

Hamilton, M., Thompson, E. N., and Wisniewski, T. K. M. (1964). The role of blood-pressure control in preventing complications of hypertension. Lancet, 1, 235.

Hawthorne, V. M. (1975). Screening for disease. (Letter.) Lancet, 1, 326.

Hawthorne, V. M., Gillis, C. R., Lorimer, A. R., Calvert, F. R., and Walker, T. J. (1969). Blood pressure in a Scottish island community. British Medical fournal, 4, 651.

Hawthorne, V. M., Gillis, C. R., and Maclean, D. S. (1972). Monitoring health in Scotland. International fournal of Epidemiology, 1, 369.

Hawthorne, V. M., Greaves, D. A., and Beevers, D. G. (1974). Blood pressure in a Scottish town. British Medical Fournal, 3, 600 .

Hodes, C., Rogers, P. A., and Everitt, M. G. (1975). High blood pressure: detection and treatment by general practitioners. British Medical fournal, 2, 674.

Miall, W. E., and Brennan, P. J. (1975). A pilot trial of treatment for mild hypertension; interim report of the Medical Research Council's trial in Britain. Clinical Science and Molecular Medicine, 48, 165s.

Mitchell, J. R. A. (1959). Nose-bleeding and high blood pressure. British Medical fournal, 1, 25.

Peart, W. S. (1973). The organisation of a multi-centre randomised control therapeutic trial for mild to moderate hypertension. Clinical Science and Molecular Medicine, 45, 67s.

Robinson, J. O. (1962). Symptoms and the discovery of high blood pressure. British fournal of Clinical Psychology, 2, 56.

Rose, G. A., Holland, W. W., and Crowley, E. A. (1964). A sphygmomanometer for epidemiologists. Lancet, 1, 296. 
Sackett, D. L. (1974). Cardiovascular diseases. Lancet, 2, 1189.

Sackett, D. L., and Holland, W. W. (1975). Controversy in the detection of disease. Lancet, 2, 357.

Sainsbury, P. (1964). Neuroticism and hypertension in an out-patient population. Fournal of Psychosomatic Research, 8, 235.

Schnohr, P., and Hansen, A. T. (1975). Mass screening for hypertension in Copenhagen supermarkets. Lancet, 2, 969.

Schoenberger, J. A., Stamler, J., Shekelle, R. B., and Shekelle, S. (1972). Current status of hypertension control in an industrial population. Fournal of the American Medical Association, 222, 559.

Silverberg, D. S., Smith, E. S. O., Juchli, B., and VanDorsser, E. (1974). Use of shopping centres in screening for hypertension. Canadian Medical Association fournal, 111, 769.

Sinclair, R. G. (1969). Hypertension: a study in general practice. Fournal of the Royal College of General Practitioners, 17, 17.

Stewart, I. M. D. (1953). Headache and hypertension. Lancet, 1, 1261.

Taguchi, J., and Freis, E. D. (1974). Partial reduction of blood pressure and prevention of complications in hypertension. New England fournal of Medicine, 291, 329.

Turner, R. W. D., and Ball, K. (1975). Screening for hypertension. (Letter.) Lancet, 1, 628-629.

Veterans Administration Co-Operative Study Group on Antihypertensive Agents (1967). Effects of treatment on morbidity in hypertension I: Results in patients with diastolic blood pressures averaging 115 through 129 mmHg. fournal of the American Medical Association, 202, 1028.

Veterans Administration Co-Operative Study Group on Antihypertensive Agents (1970). Effects of treatment on morbidity in hypertension II : Results in patients with diastolic blood pressure averaging 90 through $114 \mathrm{mmHg}$. fournal of the American Medical Association, 213, 1143.

Waters, W. E. (1971). Headache and blood pressure in the community. British Medical fournal, 1, 142.

Weiss, N. S. (1972). Relation of high blood pressure to headache, epistaxis, and selected other symptoms. New England fournal of Medicine, 287, 631.

Wilber, J. A., and Barrow, J. G. (1972). Hypertension-a community problem. American fournal of Medicine, 52, 653.

Wilhelmsen, L. (1975). Treatment of hypertension in a Swedish community-the problem of borderline hypertension. Acta Medica Scandinavica, Suppl. 576, p. 99.

Requests for reprints to Dr. D. G. Beevers, M.R.C. Blood Pressure Unit, Western Infirmary, Glasgow G11 6NT. 